\title{
Model Pemberdayaan Literasi Tuberculosis Pada Siswa di SD N Tanjungmas
}

\author{
Aprianti ${ }^{1}$, Kismi Mubarokah $^{2}$ \\ ${ }^{1,2}$ Fakultas Kesehatan Universitas Dian Nuswantoro \\ E-mail: ${ }^{1}$ aprianti@dsn.dinus.ac.id, ${ }^{2}$ kismi.mubarok@gmail.com
}

\begin{abstract}
Abstrak
Puskesmas Bandarharjo adalah puskesmas dengan jumlah kasus tuberculosis yang tinggi di Kota Semarang.Ttahun 2017 jumlah kasus tuberculosis pada anak sebanyak 9 kasus. Kelurahan Tangjung mas memiliki kadatan hunian yang tinggi dan terdapat keluarga miskin paling banyak yaitu $153 \mathrm{KK}$. Kondisi miskin dipengaruhi oleh tingkat pendapatan masyarakat. Pekerjaan paling banyak Tanjung Mas adalah buruh pabrik. Kondisi tersebut meningkat risiko terjadinya kasus tuberculosis khususnya tuberculosis pada anak. Anak merupakan tahapan dengan tugas perkembangannya adalah mendapatkan pendidikan, sehingga waktu produktif bagi anak paling banyak dilakukan di sekolah. Sekolah merupakan salah satu tempat yang efektif dan efisien untuk melakukan pemberdayaan literasi tuberkulosis pada anak. Oleh karena itu pemberdayan yang akan dilakukan terfokuskan pada pembuatan model pemberdayaan literasi tuberculosis pada anak di SD N Tanjungmas. Luaran yang didapatkan dari kegiatan pengabdian masyarakat ini pengetahuan guru meningkat dengan efektifitas program, sedang dengan nilai gain score 0,69. Flipchart TAGAR (Tuberculosis tingkat dasar) didistribusikan sebanyak 20 buah untuk seluruh guru dan arsip sekolah, siswa sangat antusias mengikut lomba mewarnai dengan tema pesan pencegahan tuberculosis sebanyak 40 pot telah terwarnai. Diharapkan dengan guru dan siswa yang teredukasi dapat menurunkan kasus tuberculosis, segera mendapatkan pengobatan serta meningkatkan perilaku pencegahan tuberculosis.
\end{abstract}

Kata kunci: Literasi tuberculosis, siswa sekolah dasar, Edukasi

\begin{abstract}
Bandarharjo Primary health care have high number of tuberculosis cases in Semarang City. In 2017 the number of tuberculosis cases in children was 9 cases. Tangjung Mas has a high occupancy rate and there are poor families at most, namely 153 families. Poor conditions are influenced by the level of community income. Tanjung Mas' most occupations are factory workers. This condition increases the risk of tuberculosis cases, especially tuberculosis in children. Children are a stage whose developmental task is to get education, so that most productive time for children is in school. Schools are one of the most effective and efficient places to empower children with tuberculosis literacy. Therefore, the empowerment that will be carried out is focused on making a tuberculosis literacy empowerment model in children at SD $N$ Tanjungmas. The output obtained from this community service activity increased teacher knowledge with the effectiveness of the program, with a gain score of 0.69. Twenty TAGAR (basic level tuberculosis) flipcharts were distributed to all teachers and school archives. Students were very enthusiastic about participating in a coloring contest with the theme of tuberculosis prevention messages as many as 40 pots had been colored. It is hoped that educated teachers and students can reduce tuberculosis cases, get treatment immediately and improve tuberculosis prevention behavior.
\end{abstract}

Keywords: Tuberculosis literacy, elementary students, education 


\section{PENDAHULUAN}

Indonesia termasuk kedalam lima negara dengan kasus TB tertinggi di dunia dengan jumlah kasus baru TB di Indonesia sebanyak 420.994 kasus pada tahun 2017. Data TBC mengalami kenaikan menjadi 511.873 kasus pada tahun 2018. Jawa Tengah termasuk kedalam provinsi dengan jumlah kasus TBC terbanyak kedua yaitu sebesar 67.063 kasus.[1] Sebagai salah satu negara dengan beban TB yang tinggi, Indonesia perlu melakukan strategi akselerasi guna mencapai eliminasi sebagaimana tercantum di dalam target Sustainable Development Goals. Masalah Tuberkulosis di Indonesia tidak mungkin diselesaikan oleh sektor kesehatan sendiri. Sebab, pengendalian faktor risiko Tuberkulosis terkait erat dengan berbagai faktor yang menjadi tanggung jawab sektor lain, antara lain : (a) lingkungan yang padat dan kumuh, (b) penyediaan rumah sehat dengan ventilasi cukup, (c) pembudayaan perilaku bersih dan sehat pada murid sekolah, (d) peningkatan tingkat sosial, ekonomi, dan pendidikan, dan (e) pembiayaan program yang saat ini masih banyak tergantung kepada bantuan donor.

Penderita TB BTA (semua tipe) pada tahun 2018 di Kota Semarang sejumlah 4.252 kasus, dengan persentase TB Semua Tipe pada laki-laki sebanyak 2.308 kasus (54\%) lebih besar dari pada perempuan sebanyak 1.944 kasus (46\%).[2] Hal ini disebabkan karena (fakta kwalitatif) pada laki-laki lebih intens kontak dengan faktor risiko dan kurang peduli terhadap aspek pemeliharaan kesehatan individu dibandingkan dengan wanita. Penderita TB semua tipe. kelompok usia 15-34 sebanyak 1.191 kasus (28\%), kelompok usia 55-64 sebanyak 582 kasus (14\%) dan kelompok usia $>65$ tahun sebanyak 365 kasus (9\%). Kasus TB semua tipe banyak terjadi pada kelompok usia produktif, upaya serius dalam pencegahan dan pengobatan tetap harus dilakukan karena dapat menularkan pada segala kelompok umur. Pada kelompok usia bayi dan anak sebanyak 884 kasus (20\%) telah menderita TB, Angka ini bisa bertambah apabila tidak dilakukan upaya pencegahan sejak dini pada kelompok anak.[3]

Puskesmas Bandarharjo merupakan salah satu puskesmas dengan jumlah kasus TB pada anak yang tinggi di Kota Semarang. Pada tahun 2016 jumlah kasus TB pada Anak di Puskesmas Bandarharjo sebanyak 13 kasus. Pada tahun 2017 jumlah kasus TB pada anak mengalami penurunan yaitu sebanyak 9 kasus.[2] Meskipun demikian kasus TB pada Anak masih tinggi, terlebih lagi jika tidak ditangani dengan tepat akan memungkinkan anak untuk relaps serta menularkan kepada anak yang lain.

Anak yang terinfeksi TB tidak selalu akan mengalami sakit TB, 10\%-15\% yang terinfeksi TB akan menjadi sakit TB. Pemberian terapi pencegahan pada anak infeksi TB mengurangi kemungkinan berkembangnya sakit TB. Anak yang terinfeksi tuberkulosis dapat memperlihatkan hasil uji tuberkulin positif tanpa ditemukan kelainan manifestasi klinis, radiologis, ataupun laboratorium. Selain itu, penilaian yang akurat mengenai penyakit TB pada anak saat ini masih terhambat oleh data surveilans yang masih terbatas. Sulitnya menegakkan diagnosis TB pada anak mengakibatkan data TB anak sangat terbatas. Sulitnya konfirmasi diagnosis TB pada anak mengakibatkan penanganan TB anak terabaikan Anak yang sudah terinfeksi TB harus dicegah untuk berkembang menjadi sakit tuberkulosis.[4]

Faktor yang memengaruhi seseorang anak sakit TB adalah daya tahan tubuh yang lemah, sosial dan ekonomi yang rendah, kemiskinan, perumahan yang kurang memenuhi syarat kesehatan, kepadatan penduduk, besar keluarga, gizi kurang, serta kebersihan lingkungan. Disamping itu, ada faktor lain, seperti sumber penularan penyakit, usia, tidak mendapat imunisasi, virulensi serta jumlah kuman memegang peran penting dalam sakit TB paru. Berdasarkan penelitian yang dilakukan oleh Kamalina Yustikarini faktor yang berhubungan dengan kejadian TB pada anak di Semarang adalah Riwayat kontak TB dan kepadatan hunian.[4]

Kelurahan Tanjungmas merupakan kelurahan berada di Kecamatan Semarang Utara. Kecamatan Semarang Utara merupakan salah satu tempat di Kota Semarang yang masih mengalami genangan rob. Wilayah Tanjung Mas memiliki genangan yang paling luas dibanding Kelurahan lain di Kecamatan Semarang Utara, yaitu seluas 337,06 ha. Luas wilayah dan tinggi genangan ini memungkinkan dampak lingkungan. Salah satunya ditunjukkan dengan banyaknya 
SPAL yang terendam rob, khususnya di wilayah Tanjung Mas yang terdapat 32 rumah dengan kondisi SPAL terendam rob. Hal ini merupakan salah satu komponen yang mempengaruhi nilai IKL di KelurahanTanjung Mas masih buruk dan paling rendah di WIlayah Kerja Puskesmas Bandarharjo. Selain itu, Kelurahan Tangjung mas memiliki kadatan hunian yang tinggi dan terdapat keluarga miskin paling banyak yaitu $153 \mathrm{KK}$. Kondisi miskin ini tentunya dipengaruhi oleh tingkat pendapatan masyarakat sekitar. Di mana mata pencaharian paling banyak Tanjung Mas selain IRT adalah buruh pabrik. Kondisi tersebut meningkat risiko terjadinya kasus TB khususnya TB pada anak.[5]

Anak merupakan tahapan dengan tugas perkembangannya adalah mendapatkan pendidikan, sehingga waktu produktif bagi anak paling banyak dilakukan di sekolah.[6] Sekolah merupakan salah satu tempat yang efektif dan efisien untuk melakukan pemberdayaan literasi tuberkulosis pada anak. Oleh karena itu pemberdayan yang akan dilakukan terfokuskan pada pembuatan model pemberdayaan literasi TB pada anak di SD N Tanjungmas.

Permasalahan yang dialami SD N Tanjungmas adalah literasi TB yang masih rendah, belum adanya media KIE yang efektif dan menyenangkan bagi anak - anak. Persepsi guru yang masih menilai jika permasalahan TB merupakan urusan sektor kesehatan sehingga guru tidak perlu terlibat dalam pencegahan TB pada anak. Selain itu, pertugas kesehatan yang masih kurang berkoordinasi dengan sekolah terkait pencegahan TB pada anak, karena masih terfokuskan pada masalah personal hygiene membuat TB pada anak belum menjadi program prioritas bagi puskesmas. Sehingga optimalisasi sekolah sebagai suatu tempat yang efektif dan efisien untuk pemberdayaan TB belum terlaksana.

\section{METODE}

Kerucut Edgar dale menjelaskan jenis media gambar berwarna dengan melibatkan audience ke dalam berdiskusi kelompok kecil mempunyai kemungkinan $70 \%$ dapat mengingat informasi yang disampaikan. Selain itu dari psikologis anak akan lebih memahami suatu informasi jika diberikan media pembelajaran dengan bermain. Dengan memasukkan konsep ice breaking yang dikemas dalam games permainan-permainan menarik, anak akan dengan mudah menangkap materi dan memahami informasi yang disampaikan.[7]

Untuk mengatasi permasalahan di atas, model pemberdayaan yang akan dilakukan adalah dengan melakukan pemberdayaan kepada anak - anak SD untuk meningkatkan literasi tuberculosis pada anak SD melalui pengembangan kreatifitas anak - anak dengan konsep bermain dan belajar yaitu mewarnai dan melukis pada media pot bunga yang dapat sekaligus digunakan sebagai media untuk membuat asri sekolah. Hasil karya anak - anak tersebut akan diabadikan dengan dipasang di tempat - tempat strategis sekolah sehingga anak - anak akan selalu mengingat informasi - informasi kesehatan terkait TB. Di akhir pemberdayaan akan dilakukan dengan perjanjian kerjasama yaitu berupa komitmen guru untuk mau berpartisipasi dalam usaha pencegahan dan penemuan kasus TB pada anak. Adapun metode pelakasanaanya adalah sebagai berikut :

\section{a. Advokasi Sekolah}

Yaitu kerjasama dan komitmen dengan sekolah untuk melakukan upaya pencegahan dan membantu petugas kesehatan dalam menemukan kasus TB pada anak.

b. Training of trainer Guru

Bertujuan untuk meningkatkan pemahaman guru tetang tuberculosis dan mengenalkan media TAGAR (tuberculosis tingkat dasar) sebagai media guru dalam menjelaskan tentang tuberculosis kepada anak SD.

c. Lomba Mewarnai anak SD

Mengembangan media KIE (Komunikasi Informasi dan Edukasi) hasil karya anak - 
anak SD tersebut berupa menggambar pada pot bunga yang berisi tentang pencegahan TB khususnya pada anak. Pot bunga akan didistribusikan ke rumah siswa dengan bantuan guru SD selama siswa masih belajar dari rumah. Media yang telah dikembangkan oleh anak - anak akan diletakakn di tempat - tempat strategis sekolah sehingga anak - anak akan selalu mengingat upaya untuk pencegahan TB dan mampu merubah perilaku mereka untuk kedepannya.

\section{HASIL DAN PEMBAHASAN}

Pelaksanaan kegiatan pengabdian masyarakat "Model Pemberdayaan Literasi Tuberculosis Pada Guru Dan Siswa Di SD N Tanjung Mas" berjalan dengan lancer. Peserta seluruh guru mengikuti kegiatan pengabdian dan Siswa yang dilibatkan sebagai peserta oleh pihak sekolah adalah siswa kelas V saja karena situasi pandemi sehingga tidak bisa melibatkan seluruh siswa, sehinga informasi yang diberikan terkait tuberculosis lebih bisa fokus dan diterima oleh siswa. Pada umumnya, anak - anak seusia 9-12 tahun memiliki sifat selalu ingin menyampaikan apa yang diterima dan diketahuinya dari orang lain. Anak - anak yang berada pada kelas tinggi, memiliki rasa ingin tahu, ingin belajar, dan minat terhadap sesuatu. Siswa kelas $\mathrm{V}$, pada umumnya telah mulai mandiri dan memiliki rasa tanggung jawab pribadi serta telah menunjukkan sikap kritis dan rasional. Metode pelakasanaan pengabdian masyarakat ini dengan cara melakukan training of trainer (TOT) kepada guru sekolah dan memberikan lomba mewarnai kepada siswa.

a. Training of trainer (TOT) kepada guru sekolah

Metode pengabdian dimulai dengan melakukan training of trainer (TOT) kepada guru sekolah dan memberikan media pembelajaran kepada guru sekolah unutk memudahkan guru sekolah menyampaikan materi terkait tuberculosis dasar bagi anak SD. Kegiatan TOT dimulai dengan memberikan soal pre tes kepada guru tujuan ini unutk mengetahui sejauh mana guru memhami tentang tuberculosis dan unutk mnegetahui efektifitas program TOT kepada guru, karena steelah kgegiatan TOT akan dilakukan post tes untuk mngetahui perubahan tingkat pengetahuan guru. Adapun rata - rata hasil pre test guru adalah 15,58 dan rata - rata hasil post test adalah 18,64. Untuk mengetahui efektifitas program TOT tersebut menggunakan uji gain score dengan rumus sebagai berikut :

$$
\begin{aligned}
& N \text { Gain }=\frac{\text { Skor Posttest }- \text { Skor Pretest }}{\text { Skor Ideal }- \text { Skor Pretest }} \\
& \mathrm{g}=0,69
\end{aligned}
$$

Tabel 1. Intepretasi nilai gain score

\begin{tabular}{|l|l|}
\hline Nilai N-Gain & Kategori \\
\hline $\mathrm{g}>0,7$ & Tinggi \\
\hline $0,3 \leq \mathrm{g} \leq 0,7$ & Sedang \\
\hline $\mathrm{g}<0,3$ & Rendah \\
\hline
\end{tabular}

Sumber : Melzer dalam Syahfitri, 2008

Sehingga dapat disimpulkan efektifitas program TOT kepada guru memiliki efektifitas sedang. Hal ini disebabkan karena keterbatasan waktu dimana tim hanya memiliki waktu selama satu hari untuk melakukan TOT kepada guru. Setelah melakukan pre test kepada guru dilakukan penyegaran materi terkait tuberculosis kepada guru SD. Kegiatan ini lebih benyak dilakukan dengan diskusi kepada guru. Banyak guru yang bertanya terkait mitos dan fakta tentang tuberculosis yang ada dimasyarkat serta menceritakan tentang peserta didiknya yang pernah terkena tuberculosis. Kemudian dilakukan ice breaking agar membuat peserta TOT tetap fokus mengikuti pelatihan. 


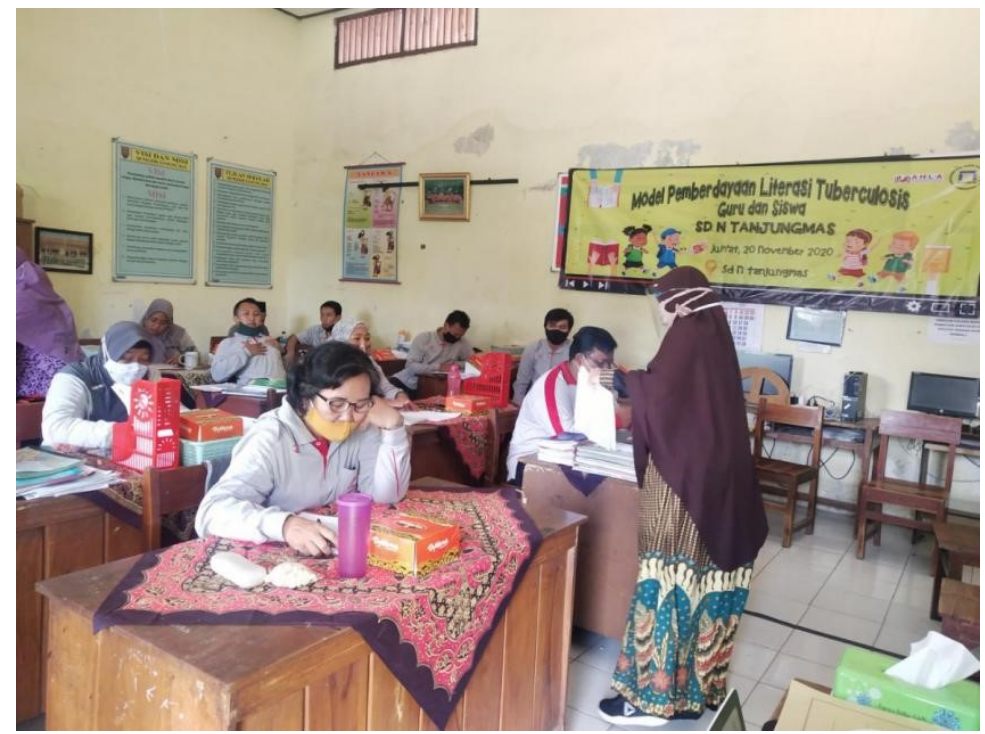

Gambar 1. Training of trainer Guru SD

Kegiatan selanjutnya adalah dengan memberikan media pembelajaran berupa lembar balik edukasi kit bagi guru sekolah dasar yang berjudul "TAGAR" (Tuberculosis tingkat dasar). Pemberian media ini bertujuan agar memudahkan guru dalam meyampaikan materi tentang tuberculosis kepada anak didiknya. Lembar balik TAGAR ini berisikan informasi dasar tentang tuberculosis dan terfokuskan pada cara pencegahan yang dapat dilakukan oleh anak - anak agar tidak tertular tuberculosis.

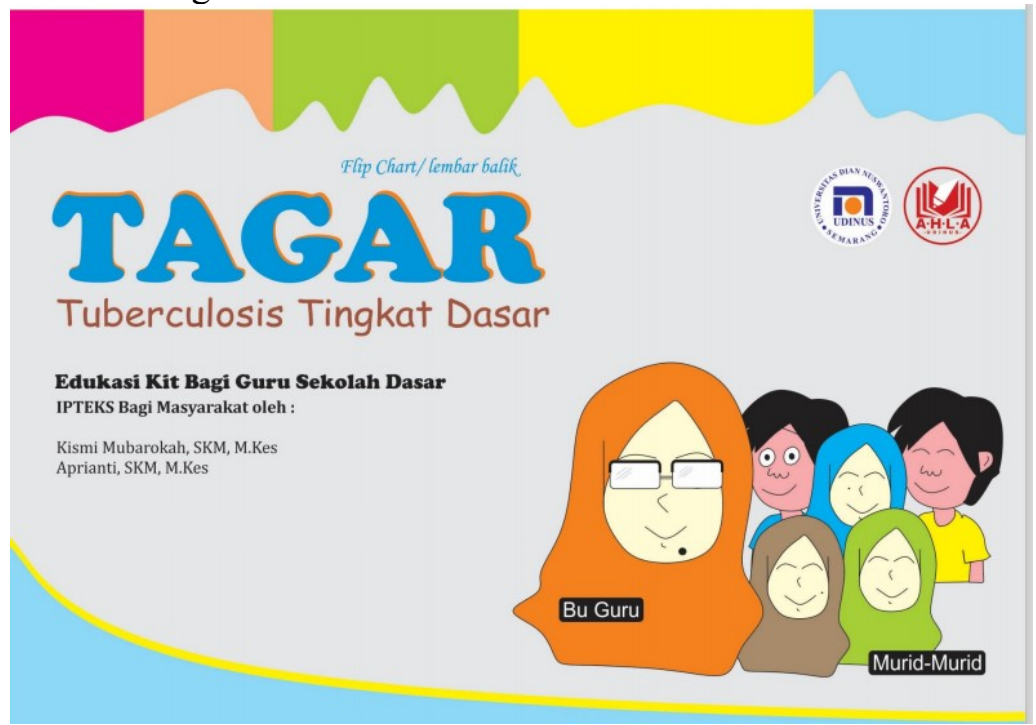

Gambar 2. Flipchart TAGAR (Tuberculosis Tingkat Dasar)

b. Lomba Mewarnai Siswa

Lomba mewarnai dengan siswa ini bertemakan pesan pencegahan tuberculosis. Kegiatan lomba berkoordinasi dengan guru kelas $\mathrm{V}$ dengan jumlah peserta siswa sebanyak 40 siswa. Kegiatan lomba dimulai dengan guru memberikan materi tentang tuberculosis dengan media TAGAR, kemudian sebagai evaluasi tingkat pemahaman siswa dilakukan dengan memberikan lomba mewarnai di pot bunga. 
Teknis lomba mewarnai dilakukan dengan membagikan pot bunga dan spidol kepada siswa, kemudian siswa membawa pulang pot dan spidol tersebut. Satu minggu kemudian siswa mengumpulan pot yang telah diwarnai kepada guru kelas. Guru kelas memilih tiga pot terbaik dan bersama tim untuk memutuskan juara satu dua dan tiga siswa untuk diberikan hadiah berupa perlengkapan sekolah.

Seluruh pot bunga yang telah diwarnai siswa kemudian dipasang disekolah sebagai penambah estetika sekolah dan juga sebagai pengingat pesan kesehatan pencagahan tuberculosis kepada siswa. Lomba mewarnai selain sebagai evaluasi keberhasilan guru dalam menyampaikan pesan pencegahan tuberculosis juga sebagai wadah kreatifitas siswa, terlebih lagi selama pandemic yang membuat siswa terkadang merasa tertekan yang dapat berpengaruh terhadap kesehatan mental siswa.

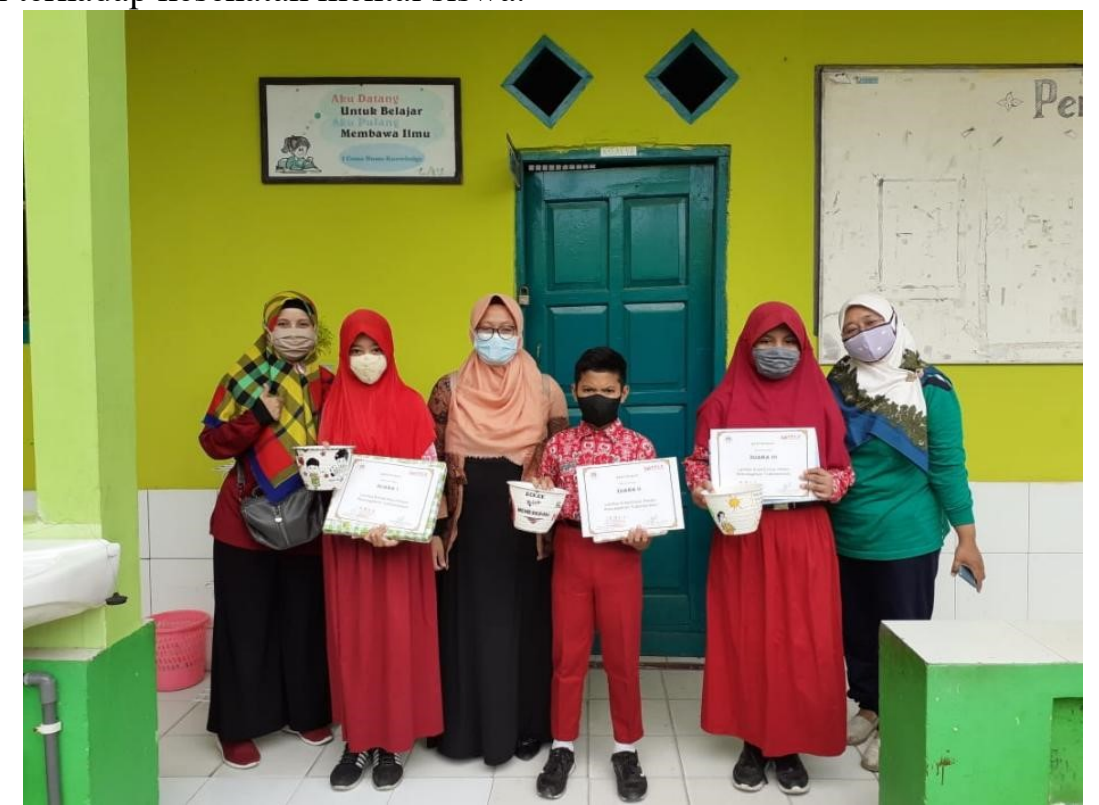

Gambar.3 Pemberian Sertifikat dan Hadiah Pemenang Lomba Mewarnai

4. KESIMPULAN DAN SARAN

1. Kesimpulan

a. Kegiatan pengabdian masyarakat di SD N Tanjung Mas berjalan dengan lancer, dengan diikuti seluruh guru SD N Tanjung Mas sebanyak 18 orang dan siswa kelas lima sebanyak 40 siswa.

b. Kegiatan training of trainer guru SD N Tanjung Mas memiliki efektifitas sedang dengan nilai gani score sebesar 0,69 .

c. Terdapat tiga siswa sebagai juara lomba mewarnai dengan tema pesan pencegahan tuberculosis

2. Saran

a. Diharapkan pihak sekolah dapat menfasilitasi wagar media TAGAR (Tuberculosis tingkat dasar) dapat dimanfaatkan guru SD kelas lain untuk memberikan edukasi kepada siswa

b. Diharapkan siswa SD dapat memanfaatkan media pot bunga yang telah dihiasi pesan pencegahan tuberculosis untuk meningkatkan literasi siswa SD tentang pencegahan tuberculosis 


\section{UCAPAN TERIMA KASIH}

Penulis mengucapkan terimakasih kepada LPPM Universitas Dian Nuswantoro yang telah memberikan hibah pengabdian masyarakat.

\section{DAFTAR PUSTAKA}

[1] Kemenkes RI, Profil Kesehatan Indonesia Tahun 2018. Jakarta: Pusat Data Kesehatan Kemenkes RI, 2018.

[2] Dinas Kesehatan Kota Semarang, Profil Kesehatan Kota Semarang Tahun 2018. Semarang: Pusat Data Kesehatan Kota Semarang, 2018.

[3] N. Nurul, F. F. Yani, and D. Basir, "Tren Kasus Tuberkulosis Anak di RSUP Dr. M. Djamil Padang Tahun 2014-2016," J. Kesehat. Andalas, vol. 8, no. 1, 2019.

[4] Y. Kamalia and M. Sidhartani, "Faktor Risiko Sakit Tuberkulosis pada Anak yang Terinfeksi Mycobacterium Tuberculosis," J. Sari Pediatr., vol. 17, no. 2, 2015.

[5] Deviar Anggina May, Budiyono, and M. Rahardjo, "Indeks Kesehatan Lingkungan di Wilayah Kerja Puskesmas Bandarharjo,” J. Kesehat. Masy., vol. 4, no. 4, 2016.

[6] S. Irawan, Psikologi Remaja. Jakarta: Raja Grafindo Persada, 1997.

[7] N. Sukidjo, Pendidikan dan Perilaku Kesehatan. Jakarta: Rineka Cipta, 2003. 